Article

\title{
How Much Does Extrinsic Motivation or Intrinsic Motivation Affect Job Engagement or Turnover Intention? A Comparison Study in China
}

\author{
Siyuan Miao ${ }^{1}$, Jaehoon Rhee ${ }^{2}$ and In Jun ${ }^{2, *}$ \\ 1 School of Economics and Management, Nanjing University of Aeronautics and Astronautics, \\ Nanjing 210016, China; sunnic315@nuaa.edu.cn \\ 2 School of Business, Yeungnam University, Gyeongbuk 38541, Korea; jrhee@gbtp.or.kr \\ * Correspondence: euinn@ynu.ac.kr
}

Received: 8 April 2020; Accepted: 24 April 2020; Published: 1 May 2020

\begin{abstract}
In recent years, the employee turnover rate for China's youth labor market has been increasing, thus sparking many social issues. By incorporating social cognitive career theory, cognitive evaluation theory and a job demands-resources model, this study aims to compare levels of employee job engagement and examine the roles of motivation in enhancing job engagement and lowering turnover intention. Further, we try to reveal the moderating effects of feedback and self-efficacy in these processes. The research was divided into two stages. In December 2017, the survey was distributed to new employees in China with a total of 409 samples. A second survey was then distributed to the same respondents one year later. The data collection for stage 2 was completed in February 2019 with a sample size of 245 . The empirical results showed that only self-efficacy moderated intrinsic motivation for job engagement. Both feedback and self-efficacy negatively moderated the influence of extrinsic motivation and positively moderated the influence of intrinsic motivation on turnover intention. The findings suggest that the key to improve employee engagement relies on maintaining their intrinsic motivation. In conclusion, implications for retaining talented young employees and suggestions for future research are discussed.
\end{abstract}

Keywords: extrinsic; intrinsic motivation; job engagement; turnover intention

\section{Research Background}

High turnover rate of talented personnel in China's youth labor market has become a serious social issue in recent years. Chinese Turnover and Salary Adjustment Report (2017) [1] showed that more than $60 \%$ of new employees quitted their jobs within two years. In 2017, the average turnover rate (of all industries) in China reached 16\% during the last year, the turnover rate of fresh graduates even reached as high as $33 \%$. This situation may bring out many social problems. From a macro-perspective, while issuing policies to encourage high-level education, the government should also encourage business to invest more in recruiting high-quality talents. The cost of recruiting and training employees is also a big expense for enterprises. On the micro level, with increased stress in life, it is vital for young people to quickly find a stable job.

The problems suggest two urgent actions: increasing young employees' job engagement during their working period, and reducing the turnover rate as much as possible. To achieve these two desired results, we should understand the current condition of young labor force in China. From 1978 to 2015, China had strictly enforced the one-child policy. The generations born during that time have been facing unprecedented economic pressure and family responsibilities. For example, if a young man was born in 1995 ( 24 years old), his parents tend to be around 55 years old. According to No. 104 
National Document (1978), China's retirement age is 60 for men, 55 for female white-collar workers and 50 for female blue-collar workers. Generally, average college students graduate at 23 to 24 years old; thus, if this young man manages to find a job and start working immediately after graduated, his parents would be retiring around the same time. As a result, this man would be taking over his family's financial responsibilities. However, as higher education becomes more and more popular, the younger generations such as the young man in the example are more likely to continue pursuing further study, thus it will likely cause a hefty financial burden on the family. Such a situation creates a common dilemma faced by the younger generations who also comprise a big portion of China's labor market. Under the circumstances, young people hesitate a lot when they are entering the workplace, and choosing their life by internal pursuit or by external pressure becomes a key issue for this generation.

According to Ryan and Deci [2], new employees can be divided into two categories based on their job motivations. One group in mainly motivated by external stimulation-this kind of young person often works with the expectation to increase their income. Most of the young people under this category may choose to find a job right after graduating from college. The other group, on the other hand, may choose to continue their studies after graduation, or realize their inside desire for higher education after they entered the workforce. This kind of young employee may not be satisfied with the present situation and choose to continue their education after a short time of work, or switch to a company that is more conducive to self-development. Scholars use "extrinsically motivated employees" and "intrinsically motivated employees" to represent these two groups of people, respectively. Based on these two types of people, this study developed a relevant research model and examined the relationship of related variables, including job characteristics, personal attitudes, and outcomes. The results are used to demonstrate the methodology to improve new employees' job engagement and reduce the turnover intention of young employees in China's labor market.

Theoretically, this phenomena would be discussed on the basis of social cognitive career theory (SCCT) [3], cognitive evaluation theory (CET) [4], and the job demands-resources model (JD-R Model) [5]. SCCT regards motivation, turnover intention and other components as separate parts of a dynamic loop; they interact with each other. On the other hand, CET believed that staying for a long time in an environment of external incentives would gradually diminish intrinsic motivation [4]. The JD-R Model assumes that job resources may play both roles of intrinsic and extrinsic motivation. This motivational process would directly or indirectly affect psychological outcomes (e.g., job engagement) and organizational outcomes (e.g., turnover intention) [6].

This research designed a comparison model of extrinsic/intrinsic motivation and job engagement one year apart. By comparing the results of the two stages, we can see how each motivation affects an employee's engagement. To take it one step further from the theoretical basis of SCCT and CET, this research will discuss the moderating effects of feedback and self-efficacy. Ryan and Deci [2] suggested that "providing motivational feedback might focus the attention on motivation and trigger reflection and improvements of motivational indicators". There might be a moderating effect from the feedback on employee's motivation and related outcomes. As a key factor in SCCT, self-efficacy was also always mentioned as an important moderator. Therefore, based on the two theories, these two factors may have impacts on overcoming the two problems. By analyzing the results of two models, we will have a general understanding of the relationship between these key variables and the degree of impact. Based on the results, we can put forward a more specific improvement plan for each issue. After collecting the data from two different periods of time, the researchers analyzed, compared, discussed, and examined them with theoretical and practical results. 


\section{Literature Review}

\subsection{Intrinsic Motivation and Extrinsic Motivation}

In employees' careers, motivation is the incentive of their professional behaviors from beginning to end [7,8], and it is also an important factor in the development of individuals and organizations [9]. For a long time, scholars have spared no effort to explore motivation from all aspects. Many studies have confirmed that intrinsic and extrinsic motivation have a great impact on their attitudes or behaviors [10]. However, what kind of motivation will have a greater impact on employees' attitudes or behaviors? Or will both kinds of motivation have the same impact on employees at different times? As the key variables in this study, the changes in them will be compared at first, and then they will be tested as important predictors, and the results will provide suggestions to achieve the research goals.

\subsection{Job Engagement-Based Feedback}

As one part of job resources, engagement appraisals provide the approach for managers and employees to evaluate the extent to which employees demonstrate behavioral engagement [11]. Positive feedback was also proved to promote engagement and performance. Feedback refers to the extent in which supervisors provide employees with useful information that enables them to learn, develop, and improve on the job [12]. Supervisors provided employees with information that reflects their behaviors and performance that leads employees to improve their performance in the future [3] and to enhance their interest in their job tasks and the tendency of learning and improvement. From the perspective of SCCT that outcomes would reinforce previous factors, frequent and accurate feedback should help to promote the previous status of employees. However, this study focused feedback on the aspect of employee's job engagement, here called job engagement-based feedback. This kind of feedback had not been discussed in detail in previous decades, but similar studies developed feedback from the performance-based feedback [13,14].

\subsection{Self-Efficacy}

One of the central variables in SCCT was self-efficacy, which received much attention in occupational research [15]. Self-efficacy referred to people's beliefs of their capabilities "to organize and execute courses of action required to attain designated types of performances" [16]. Some studies regarded self-efficacy as a fixed ability attribute, and explored its impact on employees' work behavior, including performance $[17,18]$, job engagement $[19,20]$, creativity [21,22], turnover intention $[23,24]$ and etc. In SCCT, self-efficacy was a key moderator in the loop system, and the accumulation of experience and work environment would change self-efficacy constantly. The decrease or increase in self-efficacy would have an impact on employees' workplace attitudes and behaviors [16]. Therefore, in the first stage of this study, self-efficacy was not included. One of the important reasons was that new employees may not form a relatively stable self-efficacy when they have just entered a new work environment [25]. After a period of adaptation (working environment or their task), self-efficacy would become an important factor that influences employees' attitudes and behaviors.

\subsection{Job Engagement}

Since the end of last century, a large number of studies on job engagement emerged [26]. These studies proved that job engagement was closely related to employee job satisfaction $[27,28]$, organizational commitment [29], burnout and performance [11,30], etc. Job engagement was also an important motivational variable and was still a hot topic in the industry [31,32]. Many studies have explored the antecedents of job engagement from the level of individuals and organizations, respectively [33,34]. 


\subsection{Turnover Intention}

In 2013, Singh et al. [35] conducted a study with the theoretical basis of social cognitive career theory, they adapted and integrated SCCT framework with expanding turnover intention as an important outcome in the choice model. Their study expanded a new formula of SCCT turnover relationship, which focuses on the turnover rate and behavior of new employees [35]. By following their steps, this research would look deeper into new employees' attitude and behavior, as well as to recognize turnover intention as a significant outcome of the model in SCCT.

\section{Hypotheses}

\subsection{Extrinsic/Intrinsic Motivation and Job Engagement}

The JD-R model argues that job resources may play a role as extrinsic motivation, since they are willing to make compensatory efforts to reduce work demand and promote the realization of goals. Meanwhile, they may be considered as intrinsic motivation as well, because they satisfy basic human needs for autonomy, relatedness, and competence. In both cases, this motivational process would stimulate a fulfilling, positive work-related state of mind (i.e., job engagement) [36]. Standing on this point, both motivational states could foster job engagement.

Among the few studies examining extrinsic motivation and job engagement, the results even contradict each other. Some of them show that extrinsic motivation had a positive effect on job engagement [37], or more autonomous extrinsic motivation was associated with greater engagement [38]. However, no matter in which form, extrinsic motivation and intrinsic motivation are both considered as self-regulation forms that may affect individual's engagement [39].

On the other hand, substantial research has revealed that intrinsic motivation had a direct [40], positive impact on job engagement [41]. When compared with extrinsic motivation, intrinsic motivation was more conducive to achieving sustained engagement [42], and extrinsic motivation has less influence on job engagement than intrinsic motivation [43]. This was similar to the conclusion made by Walker et al. [37] that there may be an order of influence to encourage more positive motivation and engagement.

From the perspective of CET, Deci stated that a change in the perceived locus of causality from internal to external sources resulted in a decrease in one's intrinsic motivation [4]. After conducting a one-year feedback of job engagement, the effects of extrinsic and intrinsic motivation on job engagement might transform each other subtly. Below are the hypotheses for motivations and job engagement:

Hypothesis 1a. Extrinsic motivation positively affects job engagement. At the second stage, the effect of extrinsic motivation will be increased, compared with the first stage.

Hypothesis $\mathbf{1 b}$. Intrinsic motivation positively affects job engagement. At the second stage, the effect of intrinsic motivation will be decreased, compared with the first stage.

\subsection{Extrinsic/Intrinsic Motivation and Turnover Intention}

In respect to SCCT, turnover intention can be seen as an important outcome in its choice model [35]. Since SCCT regarded individual's psychological and behavioral constructs as a dynamic loop [3], turnover intention may be affected by preceding factors in the loop as one of the outcomes. Cognitive evaluation theory was proposed to answer whether extrinsic reward detrimentally affect intrinsic motivation [44]. From this point of view, after a period of adaptation to the new work environment and tasks regardless of intrinsic motivation, new employees have experienced more or fewer external rewards or punishments, employee's intrinsic motivation may be weakened by the external rewarding environment. In this case, whether intrinsic motivation and extrinsic motivation can effectively reduce turnover intention remains to be tested. 
Previous studies have already proven the influence of intrinsic motivation [45] and extrinsic motivation [46] have on turnover intention. Kuvaas et al. (2017) [47] published an empirical study which compared intrinsic and extrinsic motivation's impact on turnover intention. The results show that intrinsic motivation correlated with positive outcomes and had a negative correlation with psychological distress and turnover intention. In contrast, extrinsic motivation had a decreasing to no correlation with positive outcomes and consistently positively correlated with negative outcomes [47]. In addition, some studies have shown that when the incentive is directly related to performance, the relationship between intrinsic motivation and performance is weaker than when the incentive is indirectly related to performance [48]. Thus, here hypothesized for the second stage:

Hypothesis 2a. Extrinsic motivation negatively affects turnover intention.

Hypothesis 2b. Intrinsic motivation negatively affects turnover intention.

\subsection{Moderating Effects of Feedback}

Since feedback was deemed as an important influencing factor of work motivation [49], the study assumed that feedback on job engagement may have an impact on extrinsic and intrinsic motivation's effects. Some studies have confirmed the moderating effect of feedback on motivation and performance [50]. Job engagement was regarded as an important factor of employee and organizational output as well as a determinant for many positive outcomes [51,52]. Thus, feedback may have moderating impacts on the relationship between motivation and job engagement and turnover intention.

A study of conventional performance feedback found that advisory practices enhanced intrinsic motivation's impacts, which led to a higher level of interest in job tasks and the tendency towards learning and improvement [12]. On the other hand, extrinsic motivation would be affected more by economic gain, social recognition, and positive appraisal. Extrinsically motivated employees may be encouraged by feedback because it is also a type of instrumental value accompanying the activity [53]. Based on the results proven strongly by previous studies and the consolidated theoretical basis, we hypothesized that:

Hypothesis 3a. Feedback on job engagement positively moderates the relationship between extrinsic motivation and job engagement.

Hypothesis $3 \mathbf{b}$. Feedback on job engagement positively moderates the relationship between intrinsic motivation and job engagement.

Hypothesis 4a. Feedback on job engagement positively moderates the relationship between extrinsic motivation and turnover intention.

Hypothesis $\mathbf{4 b}$. Feedback on job engagement positively moderates the relationship between intrinsic motivation and turnover intention.

\subsection{Moderating Effects of Self-Efficacy}

From the perspective of SCCT, self-efficacy plays a significant role in motivating behavior [54]; it was posited that self-efficacy influences behavioral intentions in direct or indirect ways [55]. Higher efficacy can sustain motivation when people believe that with continued effort they can attain their goals [56]. In the past few decades, scholars have also done some research on the self-efficacy of new employees. Newcomers with high self-efficacy may take an active approach towards role performance to demonstrate their abilities; on the contrary, individuals with low self-efficacy would be more passive in accepting the situation offered by others [57]. In his research, self-efficacy was regarded as an established ability to help newcomers adapting to new environment. In fact, according to SCCT, 
when new employees have just entered the new work environment, they had no clear judgment about the situation they were facing, but after a period of adaptation, or in other words, after experiencing the feedback loop, the employees gradually formed effective self-efficacy, which would become stronger over time [3].

Thus, in addition to previous hypotheses, here hypothesized that self-efficacy moderates the relationship between motivation and its outcomes:

Hypothesis 5a. Self-efficacy positively moderates the relationship between extrinsic motivation and job engagement.

Hypothesis $\mathbf{5 b}$. Self-efficacy positively moderates the relationship between intrinsic motivation and job engagement.

Hypothesis 6a. Self-efficacy positively moderates the relationship between extrinsic motivation and turnover intention.

Hypothesis $\mathbf{6 b}$. Self-efficacy positively moderates the relationship between intrinsic motivation and turnover intention.

Figure 1 shows research model as below:

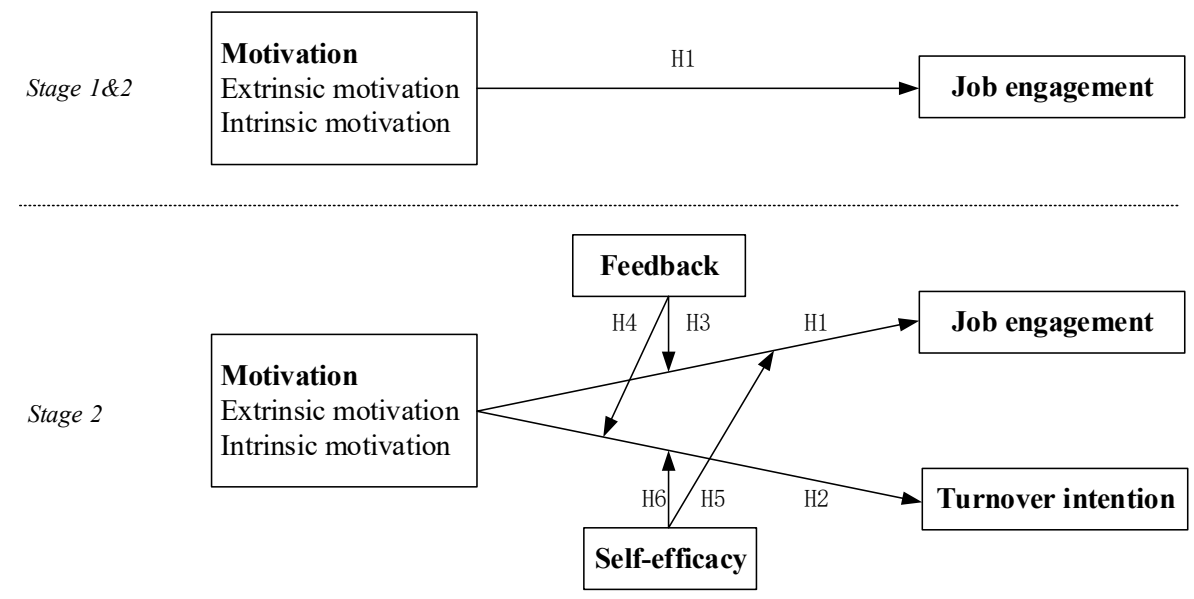

Figure 1. Research model.

\section{Methodology}

This research was conducted using a quantitative methodology. All explanatory data were derived from official websites of the departments associated with labor force in China. Survey techniques were used for data collection and measurements. The questionnaire was constructed with the relevant literature and empirical research. All items in the survey were designed on the basis of a previously validated set of measurement criteria. The questionnaires in both Chinese and English were distributed in December 2017.

The respondents were new employees who had been employed for less than three years from 2017 to 2018. A real-name system was used to track and record the changes in their intention and behavior in two separate time periods with approximately one year apart. Data were collected in two stages from Chinese new employees who were just adapting to a new work environment. We assigned a unique identification number to each respondent, and asked each respondent to leave his or her email address and telephone number in the first part of the survey. By doing so, we could approach the same respondents and collect data from them in the second part again.

Eight hundred questionnaires were distributed in December 2017 via e-mail or Internet links. The survey focused on new employees who had just graduated from university, with a few respondents being graduating students who had already started working. Specifically, we selected 8 universities in the central, northeast and southern regions of the Chinese mainland, and distributed questionnaires to the students who were close to graduation, from which we selected the respondents who had just 
found jobs as samples. In the first stage, 569 questionnaires were collected, with a response rate of $71.125 \%$. After deleting the respondents who had worked for more than three years, the total number of samples used for data analysis was 409 .

One year after we used the total samples of 409 to implement data analysis, the questionnaires designed for the second period were sent to the same respondents of stage 1. Data collection methods were the same as those of the first stage, such as mobile phone interviews or email. All data collection was completed in February 2019. Among the previous 409 respondents, 356 employees replied to the questionnaires in stage 2, yielding a response rate of $87.042 \%$. After removing 111 respondents (who had changed jobs already, or did not complete all answers), the total number of data samples used for the analysis was 245 .

\section{Sample Characteristics}

The overall sample characteristics are shown in Table 1.

Table 1. Sample characteristics.

\begin{tabular}{|c|c|c|c|c|c|}
\hline & \multirow{2}{*}{ Section } & \multicolumn{2}{|c|}{ Sample (Stage 1) } & \multicolumn{2}{|c|}{ Sample (Stage 2) } \\
\hline & & Frequency & Percentage (\%) & Frequency & Percentage $(\%)$ \\
\hline \multirow{3}{*}{ Gender } & Male & 263 & 64.30 & 135 & 55.10 \\
\hline & Female & 146 & 35.70 & 110 & 44.90 \\
\hline & Cumulative \% & 409 & 100.00 & 245 & 100.00 \\
\hline \multirow{3}{*}{ Age } & $18-25$ & 191 & 46.70 & 155 & 63.27 \\
\hline & $26-35$ & 218 & 53.30 & 90 & 36.73 \\
\hline & Cumulative \% & 409 & 100.00 & 245 & 100.00 \\
\hline \multirow{5}{*}{ Province } & Jiangsu & 137 & 33.50 & 92 & 37.55 \\
\hline & Heilongjiang & 109 & 26.65 & 51 & 20.82 \\
\hline & Shanghai & 98 & 23.96 & 76 & 31.02 \\
\hline & Others & 65 & 15.89 & 26 & 10.61 \\
\hline & Cumulative \% & 409 & 100.00 & 245 & 100.00 \\
\hline \multirow{4}{*}{ Education } & High school and below & 29 & 7.09 & 10 & 4.08 \\
\hline & Undergraduate & 266 & 65.04 & 143 & 58.37 \\
\hline & Graduate and above & 114 & 27.87 & 92 & 37.55 \\
\hline & Cumulative \% & 409 & 100.00 & 245 & 100.00 \\
\hline \multirow{13}{*}{ Department } & Student & 15 & 3.67 & - & - \\
\hline & Operating/Producing & 37 & 9.05 & 24 & 9.79 \\
\hline & Salesman & 50 & 12.22 & 33 & 13.47 \\
\hline & Marketing/PR & 46 & 11.25 & 22 & 8.98 \\
\hline & Customer service & 24 & 5.87 & 18 & 7.35 \\
\hline & Administration & 58 & 14.18 & 37 & 15.10 \\
\hline & HR & 33 & 8.07 & 13 & 5.31 \\
\hline & Accounting & 29 & 7.09 & 4 & 1.63 \\
\hline & Secretary/Assistant & 42 & 10.27 & 31 & 12.65 \\
\hline & Research/R\&D & 31 & 7.58 & 27 & 11.02 \\
\hline & $\begin{array}{c}\text { Professional } \\
\text { (Lawyer, etc.) }\end{array}$ & 36 & 8.80 & 29 & 11.84 \\
\hline & Others & 8 & 1.95 & 7 & 2.86 \\
\hline & Cumulative \% & 409 & 100.00 & 245 & 100.00 \\
\hline
\end{tabular}




\section{Variables and Measurements}

\subsection{Independent Variable}

To measure intrinsic/extrinsic motivation, eight items of two types of motivation were selected based on the respective factor loadings, which were constructed by Guay et al. [58]. Each variable corresponded to four questions. Sample items for extrinsic motivation were composed of "I do the work because I am supposed to do it", "I do the work because it is something that I have to do", "I do the work because I don't have any choice", and "I do the work because I feel that I have to do it". Items for intrinsic motivation were "I do the work because I think that this activity is interesting", "I do the work because I think that this activity is pleasant", "I do the work because this activity is fun", and "I do the work because I feel good when doing this activity". The respondents were asked to choose the answer according to the degree of agreement. Each item was measured on a 7-point Likert-type response scale. Since extrinsic and intrinsic motivations were important independent variables in both stages, the measurement would be repeated for two stages.

\subsection{Moderating Variable}

Self-efficacy was assessed using a 9-item task specific self-report measure modified for the simulation. This measure assesses self-efficacy with a 7-point Likert-type scale rather than ratings of confidence about particular aspects of the task [59,60]. Sample items for self-efficacy included: "When I set important goals for myself, I rarely achieve them".

Another moderating variable is job engagement-based feedback. The question items were developed from both definition of feedback and dimensions of job engagement [26]. The items consisted of three questions: "Does your team or supervisor regularly give you feedback containing job engagement (from physical, cognitive, or emotional perspective)?" "I accept feedback (and criticism) regarding with job engagement constructively" and "I think it is important for me to use the feedback with respect to job engagement that I received to improve myself"). All of the items were measured on a 7-point Likert-type response scale. Since this study was divided into two stages, the items designed for each variable in the first stage would be also used in the second stage.

\subsection{Dependent Variable}

The measurement of job engagement generally included the examination of how new employees devote themselves into current work. According to the definition, people employ and express themselves physically, cognitively, and emotionally during role performances [26], thus nine questions were designed from these three aspects, for instance, "I would like to do what I should do to help the company meet its goals and objectives" (physically), "When something unexpected comes up in my work, I usually know who to ask for help" (cognitively), and "I am proud to be a member of my team" (emotionally).

Turnover intention is defined as a willingness to leave the organization consciously and intentionally [61]. Turnover intention was assessed by using a three-item measure developed by Konovsky and Cropanzano [62]. Sample items were including "I often dream about getting another job that will better suit my personal needs", "I often feel frustrated when not given the opportunity at work to achieve my personal work related goals", and "I would possibly accept another job at the same compensation level should it be offered to me". A 7-point Likert-type response scale was used for each item.

\subsection{Control Variable}

With different purposes and background of research, any variable may play a role as a control variable, and some control variables appear frequently in management research [63]. Gender, for example, was often used as a control variable, because the social pressures and treatment to different genders were very different, and such experiences may cause unrelated disruptions to research. We asked the respondents to report their gender and computed a dichotomous variable 
where " 1 " represented "female" and " 0 " represented "male". Different degrees of education may affect individual's stress tolerance or attitude to work. Education was also considered as an important control variable. Formal education level reported by the respondents was scaled from 1 (basic mandatory education) to 3 (higher degree from university or college). The research also recorded the real age of the respondents. Employees of similar age, regardless of their professional knowledge, status or tenure in an organization, often share common non-work-related experience [64]. According to Ryder [65], a group of individuals of similar age presents "a unique composition and characteristics, reflecting their unique origin and historical environment". Since this study divided the subjects into two age groups, " 1 " was used to represent the group of age from 18 to 25 , and " 2 " was used to represent the group of age from 26 to 35 . Age was also listed as one of the control variables.

\section{Analysis and Results}

For the factor analysis of stage 1, the KMO values of each correlation among variables were, respectively, 0.776 and 0.850 , all supporting a well-fitting factor analysis. All factors' eigenvalues exceeded 1 . The model of second stage added three more variables. The KMO values of each group were, respectively, 0.812, 0.916, and 0.919 and all supported a well-fitting factor analysis. Cronbach's alpha values are usually used to assess the internal consistency of a variable and they should be at least 0.60 , and preferably greater than 0.80 [66]. The analysis results of all variables in both two stages, the variables' Cronbach's alpha coefficients ranged from 0.886 to 0.973 , which indicated that the internal consistency of each variable was highly acceptable.

Correlation analysis reflects the degree of a linear association between two continuous constructs, using the Pearson correlation, $r$ statistics of normal distribution should be ranged from -1.00 to +1.00 [67]. In both stages, control variables (gender, education, and age) are neither significantly correlated with independent variables or dependent variables. It also shows that extrinsic motivation is negatively correlated with intrinsic motivation $(\mathrm{r}=-0.440, p<0.01)$ and job engagement $(\mathrm{r}=-0.736$, $p<0.01)$. Intrinsic motivation in stage 1 is positively correlated with job engagement $(r=0.717$, $p<0.01)$. In the second stage, both extrinsic motivation and intrinsic motivation have positive correlations with job engagement $(\mathrm{r}=0.448, p<0.01 ; \mathrm{r}=0.509, p<0.01)$ and negative correlations with turnover intention $(\mathrm{r}=-0.200, p<0.01 ; \mathrm{r}=-0.473, p<0.01)$. Two moderators (feedback and self-efficacy) are also shown in positive correlations with job engagement $(\mathrm{r}=0.635, p<0.01 ; \mathrm{r}=0.501$, $p<0.01)$ and negative correlations with turnover intention $(\mathrm{r}=-0.310, p<0.01 ; \mathrm{r}=-0.833, p<0.01)$. Most of the significant values are less than 0.01 . Thus, it can be described that the correlation coefficients were significant. The results of multiple collinearity assessment in stage 1 and stage 2 show that all tolerance values were below 1, and all Variance Inflation Factor (VIF) values ranged from 1.241 to 1.574, below the critical value of 10. According to suggestions of the relevant assessment criteria [68], multiple collinearity here will not pose a threat to parameter estimates.

To test the hypotheses and find whether extrinsic and intrinsic motivation (independent variables) were the predictors of job engagement and turnover intention (dependent variables), a simple linear regression analysis was conducted. The standard coefficients of extrinsic motivation and intrinsic motivation of stage 1 and stage 2 were $-0.521,0.576,0.488$ and $0.619(p<0.01)$, respectively. Therefore both extrinsic and intrinsic motivation had positive impacts on job engagement in stage 2 . Figure 2 compares the influence of extrinsic and intrinsic motivation on job engagement of stage 1 to stage 2 . The dotted lines represent the relationships between the two variables in the first stage, and the solid lines represent the relationships between them in the second stage. Although the results coincide with the hypothesis in the second stage, external motivation was negatively correlated with job motivation in the first stage, thus, Hypothesis 1a is rejected and H1-b can establish. In addition, the standard coefficient of extrinsic motivation was $-0.310(p<0.01)$ with turnover intention, and the value of intrinsic motivation was $-0.530(p<0.01)$, thus, Hypothesis $2 \mathrm{a}$ and Hypothesis $2 \mathrm{~b}$ were also supported.

The moderating effects of job engagement-based feedback and self-efficacy on extrinsic and intrinsic motivation and dependent variables were also checked with the linear associations of moderator 
regression analysis. This study applied the measuring method of mean centering-(independent variable-independent variable's mean)x(moderator variable-moderator variable's mean) to test moderating effects [69]. The mean was proposed by using Baron and Kenny's three-level of investigating moderators. Level 1 was conducted with control variables and independent variables, level 2 was combined with moderating variables, then the interaction of independent variables and moderators was added in level 3.

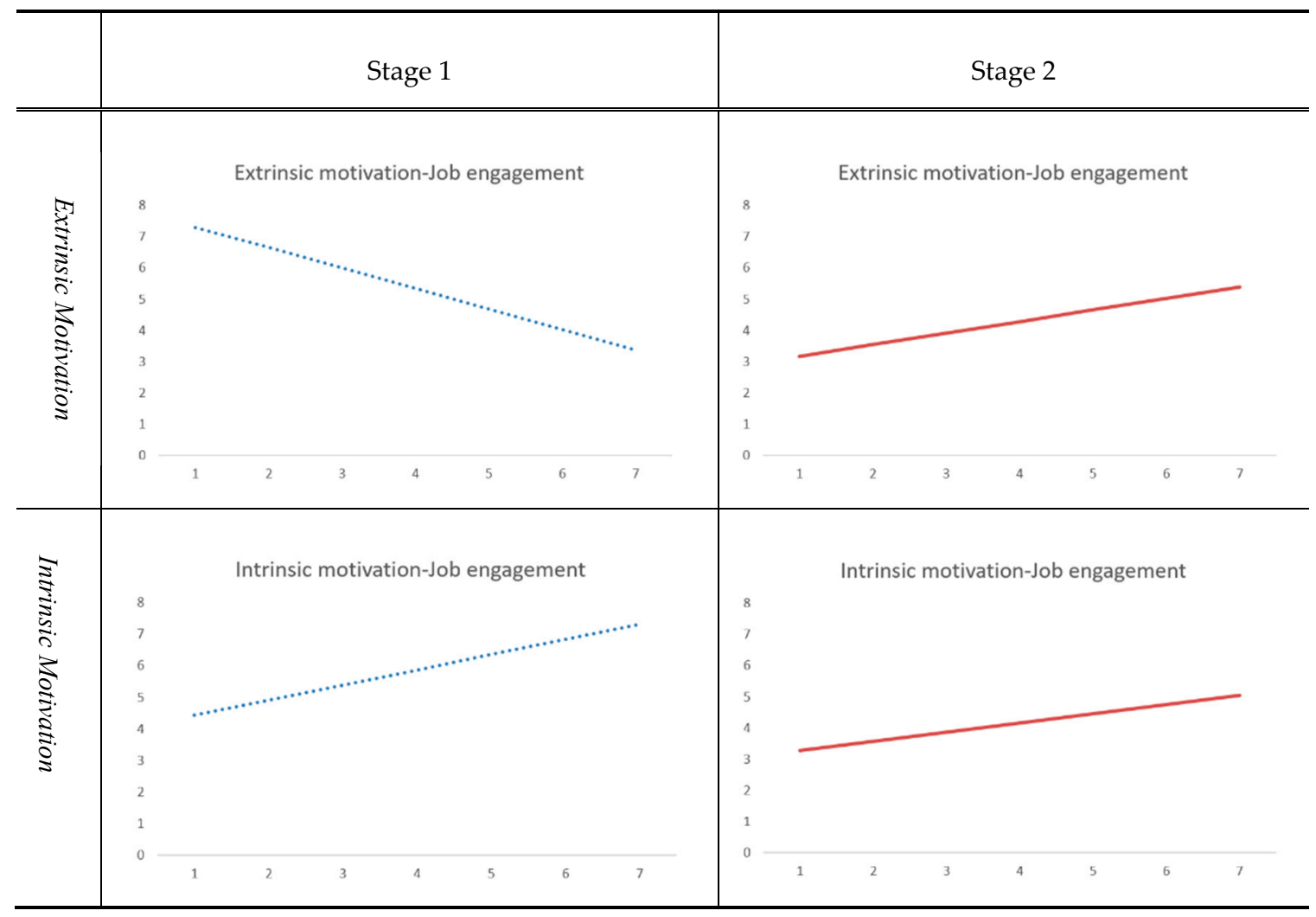

Figure 2. Effects of extrinsic/intrinsic motivation on job engagement.

The results show that both $\Delta \mathrm{R}^{2}$ of extrinsic and intrinsic motivation-job engagement did not change significantly in the third level of testing, that was to say, the interaction with feedback did not have moderating effects on the relationship between extrinsic motivation and job engagement. The regression standard coefficients demonstrated the same results. Thus, Hypothesis $3 a$ and Hypothesis $3 \mathrm{~b}$ were rejected.

To test the moderating effects of feedback on the relationship between extrinsic and intrinsic motivation and turnover intention, we found that $\Delta \mathrm{R}^{2}$ of both extrinsic and intrinsic motivation were increased significantly in the third level. At the third level, the interaction's regression coefficients of extrinsic and intrinsic motivation and feedback were, respectively, 3.075 and -2.328 , both of which reached significant level of 0.01 , indicating the moderating effects of feedback on the relationship between extrinsic and intrinsic motivation and turnover intention. Since the moderating effect of feedback was consistent with intrinsic motivation's direct effect on turnover intention, feedback was considered to moderate intrinsic motivation and turnover intention positively. Thus, Hypothesis $4 \mathrm{~b}$ was supported. However, the moderating effect of feedback was contrary to extrinsic motivation's direct effect on turnover intention, feedback negatively moderated extrinsic motivation. Thus, Hypothesis $4 \mathrm{a}$ was rejected. Table 2 shows the results of hierarchical regression analysis of moderating effect of feedback. 
Table 2. The results of hierarchical regression analysis of moderating effect of feedback.

\begin{tabular}{|c|c|c|c|c|c|c|}
\hline \multirow[b]{2}{*}{ Independent variable } & \multicolumn{6}{|c|}{ Job Engagement } \\
\hline & Level 1 & Level 2 & Level 3 & Level 1 & Level 2 & Level 3 \\
\hline Extrinsic Motivation & $0.457^{* *}$ & $0.237^{* *}$ & $0.863 * *$ & & & \\
\hline $\begin{array}{c}\text { Intrinsic Motivation } \\
\text { Moderator }\end{array}$ & & & & $0.508^{* *}$ & 0.362 ** & 0.507 \\
\hline Feedback & & $0.548^{* *}$ & $0.929 * *$ & & $0.547^{* *}$ & $0.604^{* *}$ \\
\hline Moderating effect & & & & & & \\
\hline $\begin{array}{c}\text { Extrinsic } \\
\text { Motivation } \times \text { Feedback }\end{array}$ & & & -0.858 & & & \\
\hline $\begin{array}{c}\text { Intrinsic } \\
\text { Motivation } \times \text { Feedback }\end{array}$ & & & & & & -0.171 \\
\hline$R^{2}$ & 0.211 & 0.459 & 0.469 & 0.259 & 0.532 & 0.533 \\
\hline$\Delta R^{2}$ & & 0.248 & 0.010 & & 0.273 & 0.001 \\
\hline & & & Turnove & ntention & & \\
\hline Independent variable & Level 1 & Level 2 & Level 3 & Level 1 & Level 2 & Level 3 \\
\hline Extrinsic Motivation & $-0.208^{* *}$ & -0.097 & $-2.337^{* *}$ & & & \\
\hline $\begin{array}{c}\text { Intrinsic Motivation } \\
\text { Moderator }\end{array}$ & & & & $-0.471^{* *}$ & $-0.416^{* *}$ & $1.555^{* *}$ \\
\hline Feedback & & $-0.276^{* *}$ & $-1.640^{* *}$ & & $-0.204^{* *}$ & $0.576^{* *}$ \\
\hline Moderating effect & & & & & & \\
\hline $\begin{array}{c}\text { Extrinsic } \\
\text { Motivation } \times \text { Feedback }\end{array}$ & & & $3.075^{* *}$ & & & \\
\hline $\begin{array}{c}\text { Intrinsic } \\
\text { Motivation } \times \text { Feedback }\end{array}$ & & & & & & $-2.328^{* *}$ \\
\hline$R^{2}$ & 0.048 & 0.111 & 0.247 & 0.224 & 0.262 & 0.377 \\
\hline$\Delta \mathrm{R}^{2}$ & & 0.063 & $0.136^{* *}$ & & 0.038 & $0.115^{* *}$ \\
\hline
\end{tabular}

To explain the interaction more clearly and intuitively, Figure 3 visualized the interaction effect of moderators with intrinsic motivation to job engagement and turnover intention.

Table 3 shows the results of hierarchical regression analysis of moderating effect of self-efficacy. The results show that the interaction's regression coefficient of extrinsic motivation and self-efficacy was changed slightly, but it was not enough to show that self-efficacy had moderating effect on extrinsic motivation and job engagement. $\Delta R^{2}$ was not significant either. However, the moderating effect of self-efficacy had a great impact on intrinsic motivation and job engagement. $\Delta \mathrm{R}^{2}$ was 0.169 at the significant level of 0.01 . The interaction's regression coefficient was 2.556 , representing the moderating effect of intrinsic motivation increased employee's job engagement significantly. The results prove Hypothesis $5 \mathrm{~b}$ and reject Hypothesis $5 \mathrm{a}$.

To test the results on the moderating effect of self-efficacy on extrinsic/intrinsic motivation and turnover intention, the results of the third level show that the interaction's regression coefficients of extrinsic/intrinsic motivation and self-efficacy were, respectively, 0.954 and -0.701 , both of which reached the significant level of 0.01 , indicating the moderating effects of self-efficacy with extrinsic motivation and intrinsic motivation. However, the same results as feedback's impact are seen in self-efficacy, which positively moderated the relationship between intrinsic motivation and turnover intention but negatively moderated extrinsic motivation and turnover intention. The interaction effects with self-efficacy was in the opposite direction to extrinsic motivation's direct effects. That means self-efficacy reduced the influence of extrinsic motivation on turnover intention. In conclusion, Hypothesis $6 \mathrm{a}$ was rejected and Hypothesis $6 \mathrm{~b}$ was supported. 


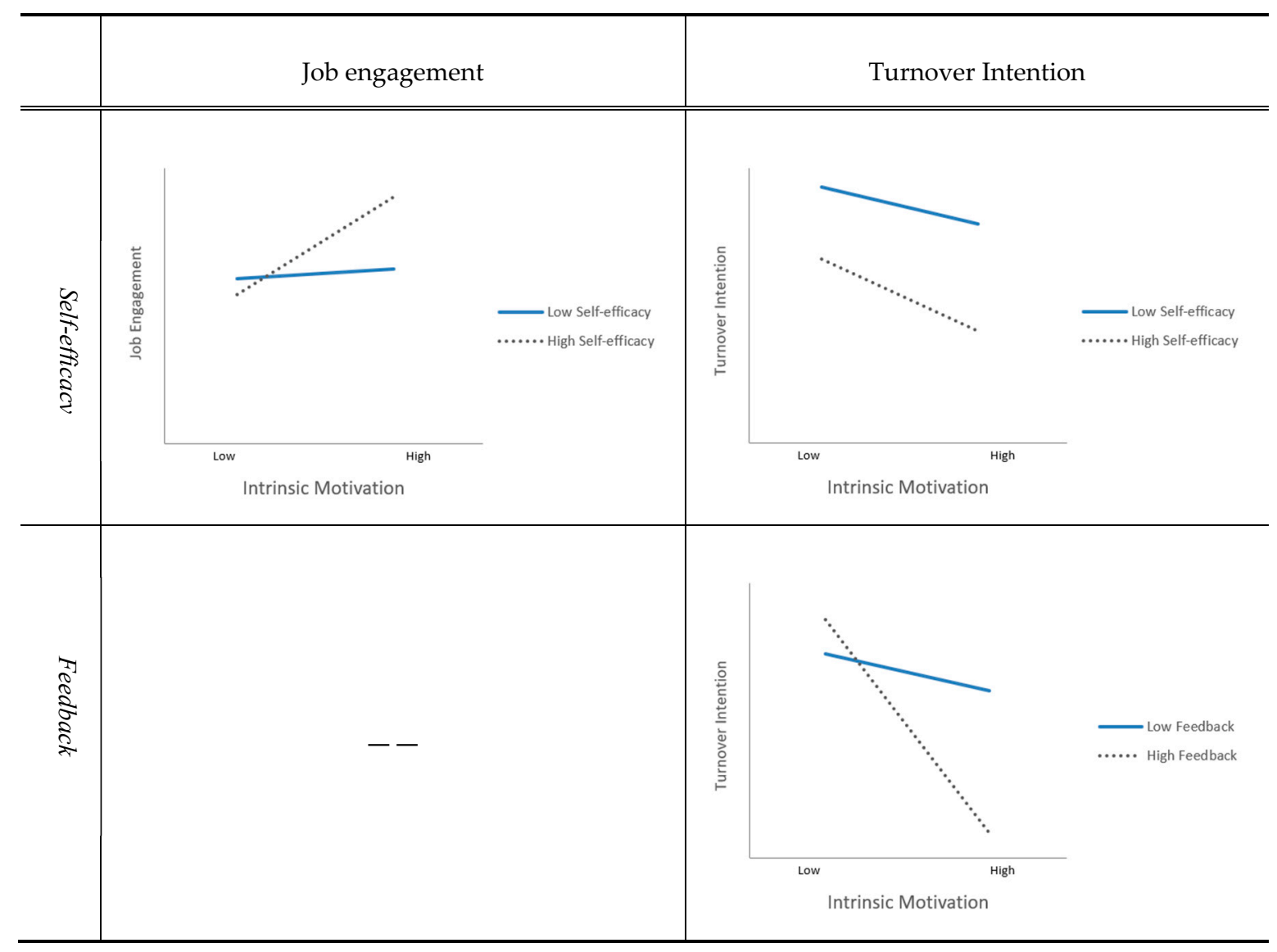

Figure 3. Moderating effects on intrinsic motivation.

Table 3. The results of hierarchical regression analysis of moderating effect of self-efficacy.

\begin{tabular}{|c|c|c|c|c|c|c|}
\hline \multirow[b]{2}{*}{$\begin{array}{c}\text { Independent } \\
\text { variable }\end{array}$} & \multicolumn{6}{|c|}{ Job Engagement } \\
\hline & Level 1 & Level 2 & Level 3 & Level 1 & Level 2 & Level 3 \\
\hline $\begin{array}{l}\text { Extrinsic } \\
\text { Motivation }\end{array}$ & $0.457^{* *}$ & $0.326^{* *}$ & 0.131 & & & \\
\hline $\begin{array}{l}\text { Intrinsic } \\
\text { Motivation } \\
\text { Moderator }\end{array}$ & & & & $0.508^{* *}$ & $0.363^{* *}$ & $-1.092^{* *}$ \\
\hline $\begin{array}{c}\text { Self-efficacy } \\
\text { Moderating } \\
\text { effect } \\
\text { Extrinsic }\end{array}$ & & $0.392 * *$ & 0.083 & & $0.351 * *$ & $-1.193^{* *}$ \\
\hline $\begin{array}{c}\text { Motivation } \\
\times \text { Self-efficacy } \\
\text { Intrinsic }\end{array}$ & & & 0.422 & & & \\
\hline $\begin{array}{l}\text { Motivation } \\
\times \text { Self-efficacy }\end{array}$ & & & & & & $2.556^{* *}$ \\
\hline $\begin{array}{c}\mathrm{R}^{2} \\
\Delta \mathrm{R}^{2}\end{array}$ & 0.211 & $\begin{array}{l}0.346 \\
0.135\end{array}$ & $\begin{array}{l}0.352 \\
0.006\end{array}$ & 0.259 & $\begin{array}{l}0.361 \\
0.102\end{array}$ & $\begin{array}{c}0.530 \\
0.169 \text { ** }\end{array}$ \\
\hline
\end{tabular}


Table 3. Cont.

\begin{tabular}{|c|c|c|c|c|c|c|}
\hline \multirow[b]{2}{*}{$\begin{array}{c}\text { Independent } \\
\text { variable }\end{array}$} & \multicolumn{6}{|c|}{ Turnover intention } \\
\hline & Level 1 & Level 2 & Level 3 & Level 1 & Level 2 & Level 3 \\
\hline $\begin{array}{l}\text { Extrinsic } \\
\text { Motivation }\end{array}$ & $-0.208^{* *}$ & -0.079 & $-0.363^{* *}$ & & & \\
\hline $\begin{array}{l}\text { Intrinsic } \\
\text { Motivation } \\
\text { Moderator }\end{array}$ & & & & $-0.471^{* *}$ & $-0.152^{* *}$ & 0.248 \\
\hline $\begin{array}{c}\text { Feedback } \\
\text { Moderating } \\
\text { effect } \\
\text { Extrinsic }\end{array}$ & & $-0.859^{* *}$ & $-1.557^{* *}$ & & $-0.771^{* *}$ & $-0.347^{* *}$ \\
\hline $\begin{array}{c}\text { Motivation } \\
\times \text { Self-efficacy } \\
\text { Intrinsic }\end{array}$ & & & $0.954 * *$ & & & \\
\hline $\begin{array}{l}\text { Motivation } \\
\times \text { Self-efficacy }\end{array}$ & & & & & & $-0.701^{* *}$ \\
\hline $\begin{array}{c}\mathrm{R}^{2} \\
\Delta \mathrm{R}^{2}\end{array}$ & 0.049 & $\begin{array}{l}0.707 \\
0.658\end{array}$ & $\begin{array}{c}0.739 \\
0.032 * *\end{array}$ & 0.224 & $\begin{array}{l}0.715 \\
0.491\end{array}$ & $\begin{array}{c}0.727 \\
0.012 \text { ** }\end{array}$ \\
\hline
\end{tabular}

\section{Conclusions and Discussion}

\subsection{Conclusions}

Based on SCCT, CET, and JD-R Model, this study conducted one-year individual-level research on newly recruited employees in China's youth labor market. This study explored the relationship between intrinsic motivation and extrinsic motivation, job engagement and turnover intention, and the moderating effects of job engagement-based feedback and self-efficacy. Methodologically, this study took a long time since it conducted the two-stage approach for the survey. The difficulty in ensuring the consistency of the two stages of the dispatched subjects was high. Thanks to the strong support of Nantong University, Guizhou Normal University, Harbin University of Technology and many other institutions, the first batch of questionnaires was distributed to graduates who had just found jobs, which increased the reliability of the research results. The data were collected twice, corresponding to each stage.

The results show that intrinsic motivation was the main driving force that motivated new employees when they entered new jobs. This result shows that intrinsic motivation always had a positive impact on job engagement. However, extrinsic motivation did not positively affect job engagement in the very beginning. When an employee had just taken over a new job, he/she had not fully adapted to the new environment, nor had s/he received enough rewards and punishments. The influence of extrinsic motivation on individual's job engagement was relatively weak at the time. When retested after one year, it was found that the impact of extrinsic motivation on job engagement was significantly increased in a positive way. Both intrinsic motivation and extrinsic motivation were crucial to job engagement, but as time passed, extrinsic motivation would gradually strengthen and intrinsic motivation would gradually weaken.

In the second stage, the negative impact of extrinsic motivation and intrinsic motivation on employees' turnover intention was also examined. This group of hypotheses were tested during the second stage because a new employee's intention to leave would be greatly influenced by various factors. Consistent with the previous examples, both test results showed a negative impact on turnover intention.

This study also examined the moderating effects of job engagement-based feedback on intrinsic motivation, extrinsic motivation, job engagement, and turnover intention, respectively. The results showed that feedback positively moderated the relationship between intrinsic motivation and turnover 
intention, and negatively moderated extrinsic motivation. Finally, as a moderator, self-efficacy was proven to have moderating effects on intrinsic motivation and job engagement. It also showed that self-efficacy positively moderated the relationship between intrinsic motivation and turnover intention and negatively moderated extrinsic motivation.

\subsection{Implications}

This result is consistent with previous studies in which the relationship between intrinsic motivation and job engagement was demonstrated, as intrinsic motivation directly affected job engagement [40], or had a positive impact on job engagement [41,70]. It is similar to what some scholars had previously proved-tangible rewards have great effects on performance, and these external forces could undermine intrinsic motivation [10,71]. By testing the moderating effects, the result is consistent with previous research that intrinsic motivations is a negative predictor for employee turnover intention [45], but contrary to Kuvaas' study that extrinsic motivation has positive associations with turnover intention [47]. This contradiction can be explained by Ryan and Deci's argument in 2000. Typically, extrinsic motivation has been characterized as a pale and impoverished form of motivation that contrasts with intrinsic motivation in the classic literature. Ryan and Deci [2] proposed that there are various types of extrinsic motivation; some represent impoverished forms of motivation and some represent active, agentic states. In this research, extrinsically motivated employees tend to make choices under external pressure and responsibilities.

The results of the analyses gave important insights into the practical implication. The findings show that extrinsic motivation positively affected job engagement in stage 2 but negatively affected it in stage 1 , while intrinsic motivation positively affects employee's engagement in both stages. These may be explained from the viewpoint of national policy with the recently issued government circular by the Ministry of Finance, Ministry of Commerce, Central Committee of the Communist Youth League and All-China Federation of Industry and Commerce, Chinese Ministry of Human Resources and Social Security. The document announced the implementation of a three-year internship program for millions of young people from January 1, 2019 in order to increase the competitiveness of employment and form a long-term mechanism conducive to promoting youth employment. This policy not only makes the youth workers feel a strong pressure shock, but also urges them to work actively to win the competition through external pressure. Big data show that the debt ratio of this group is as high as $1850 \%$, accounting for $43.48 \%$ of the consumer loan group, while more than $30 \%$ of young people repay loans with loans (news from Chinese Netease). The enormous economic pressure has become the main extrinsic motivation for the young generation to work.

The findings show that both intrinsic and extrinsic motivation would increase job engagement. However, as time goes by, external motivators would gradually weaken employee's intrinsic motivation because intrinsically motivated people are more likely to put in extra effort and have a positive attitude to get out of a miserable situation [72]. However, according to CET, a change in the perceived locus of causality from internal to external resulted in a decrease in individual's intrinsic motivation [73]. Individuals who have been externally rewarded and punished for a long time may subconsciously materialize their intrinsic motivation into external incentives. With the facts that the impact of intrinsic motivation on job engagement gradually decreased while extrinsic motivation's increased over time, we can draw inspiration from Deci's view, that it is not the extrinsic reward which motivates performance but rather the way it is managed [74]. When compared with extrinsic motivation, intrinsic motivation is more beneficial for employees' sustained job engagement. From that perspective, it will be better to keep employees intrinsically motivated in order to maintain their sustainable engagement. The second solution suggested was to decrease turnover intention with the moderating effects of feedback and self-efficacy. The results suggest that both self-efficacy and feedback of job engagement would positively impact the relationship between intrinsic motivation and turnover intention, as well as negatively impact the effects of extrinsic motivation. It is necessary to provide different feedback to employees with different motivations. The majority of feedback process models acknowledged that 
in order to make feedback effective, employees must pay close attention to the feedback information provided (e.g., [75]). Thus, how to make the feedback or other information provided by the organization be absorbed and accepted in a timely and effective manner is also a difficult problem that needs to be improved.

\subsection{Limitations and Avenues for Future Research}

Although this study has achieved the expected results, there were still many aspects that can be improved or further studied in future research. Firstly, apart from SCCT and CET, many other theories can also be applied to this research model. For example, attribution theory was used to explain the relationship between motivation and job engagement $[76,77]$ with an emphasis on the education field. Reinforcement theory also emphasized that the outcomes can react to previous existing behaviors [78], which is similar to the viewpoint of dynamic loop in SCCT. Secondly, this study aimed to explore the psychological and behavioral changes of newly-recruited employees; although most of the respondents were young people who had just found a job, there were still a few middle-aged people who had just entered into a new work environment. However, on a broader spectrum, this study could not fully represent the situation of China's youth labor market. In the future, similar studies can be carried out with more specific selections and clearer targets. Due to geographical reasons, the size of the samples was very limited compared to the entire human resources market in China. Although efforts have been made to expand the scope of this research in order to enhance the credibility and representativeness, it remained difficult to achieve in such a limited time frame. In addition, economic and cultural gaps between different regions should also be considered as factors or be controlled. Future studies can be expanded with more considerations to identify different areas and their populations. Even though the reliability and validity of the items designed for the job engagement-based feedback part have been confirmed, they were only tested by the individuals themselves, which means the subjective evaluation was mixed in the process of answering. If the researchers want to carry this type of research further or get more accurate responses, they should interview the supervisors of individual employees so that the results would be more objective. Last but not least, this study only examined feedback and self-efficacy as moderators, but some research also suggested that feedback and self-efficacy can be predictors of motivation [14,79]. From that viewpoint, feedback and self-efficacy may be used to explain why motivation changed in two stages.

Author Contributions: S.M., J.R. and I.J. contributed to designing the conceptual model and methodology, advising literature review and interpreting the survey results together. All authors have read and agreed to the published version of the manuscript.

Funding: This research was supported by the Fundamental Research Funds for the Central University (No. NJ2020046, 2020.01 2021.12, Nanjing University of Aeronautics and Astronautics) and the Fundamental Research Funds for the Central University (No. NP2019201).

Conflicts of Interest: The authors declare no conflicts of interest.

\section{References}

1. NASDAQ: JOBS. Available online: http://www.chinanews.com/cj/2016/12-19/8097919.shtml (accessed on 19 December 2016).

2. Ryan, R.M.; Deci, E.L. Intrinsic and extrinsic motivations: Classic definitions and new directions. Contemp. Educ. Psychol. 2000, 25, 54-67. [CrossRef]

3. Lent, R.W.; Brown, S.D.; Hackett, G. Social cognitive career theory. Career Choice Dev. 2002, 4, $255-311$.

4. Deci, E.L.; Ryan, R.M. The general causality orientations scale: Self-determination in personality. J. Res. Personal. 1985, 19, 109-134. [CrossRef]

5. Demerouti, E.; Bakker, A.B.; Nachreiner, F.; Schaufeli, W.B. The job demands-resources model of burnout. J. Appl. Psychol. 2001, 86, 499-512. [CrossRef] [PubMed]

6. Schaufeli, W.B.; Bakker, A.B. Job demands, job resources, and their relationship with burnout and engagement: A multi-sample study. J. Organ. Behav. 2004, 25, 293-315. [CrossRef] 
7. Murdock, K. Intrinsic motivation and optimal incentive contracts. RAND J. Econ. 2002, 33, 650-672. [CrossRef]

8. Fehr, E.; Herz,H.; Wilkening, T. The lure of authority: Motivation and incentive effects of power. Am. Econ. Rev. 2013, 103, 1325-1359. [CrossRef]

9. Shahzadi, I.; Javed, A.; Pirzada, S.S.; Nasreen, S.; Khanam, F. Impact of employee motivation on employee performance. Eur. J. Bus. Manag. 2014, 6, 159-166.

10. Sansone, C.; Harackiewicz, J.M. Intrinsic and Extrinsic Motivation: The Search for Optimal Motivation and Performance; Elsevier: Amsterdam, The Netherlands, 2000.

11. Gruman, J.A.; Saks, A.M. Performance management and employee engagement. Hum. Resour. Manag. Rev. 2011, 21, 123-136. [CrossRef]

12. Zhou, X.S.; Huang, T.S. Relevance feedback in image retrieval: A comprehensive review. Multimed. Syst. 2003, 8, 536-544. [CrossRef]

13. Gichuhi, A.W.; Abaja, P.O.; Ochieng, I. Effect of performance appraisal on employee productivity; a case study of supermarkets in Nakuru Town, Kenya. Asian J. Bus. Manag. Sci. 2013, 2, $42-58$.

14. Guo, Y.; Liao, J.; Liao, S.; Zhang, Y. The mediating role of intrinsic motivation on the relationship between developmental feedback and employee job performance. Soc. Behav. Pers. 2014, 42, 731-741. [CrossRef]

15. Bonitz, V.S.; Larson, L.M.; Armstrong, P.I. Interests, self-efficacy, and choice goals: An experimental manipulation. J. Vocat. Behav. 2010, 76, 223-233. [CrossRef]

16. Bandura, A. The explanatory and predictive scope of self-efficacy theory. J. Soc. Clin. Psychol. 1986, 4, 359-373. [CrossRef]

17. Bell, B.S.; Kozlowski, S.W. Goal orientation and ability: Interactive effects on self-efficacy, performance, and knowledge. J. Appl. Psychol. 2002, 87, 497-505. [CrossRef] [PubMed]

18. Judge, T.A.; Jackson, C.L.; Shaw, J.C.; Scott, B.A.; Rich, B.L. Self-efficacy and work-related performance: The integral role of individual differences. J. Appl. Psychol. 2007, 92, 107-127. [CrossRef]

19. Xanthopoulou, D.; Bakker, A.B.; Demerouti, E.; Schaufeli, W.B. Reciprocal relationships between job resources, personal resources, and work engagement. J. Vocat. Behav. 2009, 74, 235-244. [CrossRef]

20. Innstrand, S.T. Occupational differences in work engagement: A longitudinal study among eight occupational groups in Norway. Scand. J. Psychol. 2016, 57, 338-349. [CrossRef]

21. Jaussi, K.S.; Randel, A.E.; Dionne, S.D. I Am, I Think I Can, and I Do: The role of personal identity, self-efficacy, and cross-application of experiences in creativity at work. Creat. Res. J. 2007, 19, 247-258. [CrossRef]

22. Gong, Y.; Huang, J.C.; Farh, J.L. Employee learning orientation, transformational leadership, and employee creativity: The mediating role of employee creative self-efficacy. Acad. Manag. J. 2009, 52, 765-778. [CrossRef]

23. Lai, M.C.; Chen, Y.C. Self-efficacy, effort, job performance, job satisfaction, and turnover intention: The effect of personal characteristics on organization performance. Int. J. Innov. Manag. Technol. 2012, 3, 387-391. [CrossRef]

24. Park, I.J.; Jung, H. Relationships among future time perspective, career and organizational commitment, occupational self-efficacy, and turnover intention. Soc. Behav. Personal. 2015, 43, 1547-1561. [CrossRef]

25. Chemers, M.M.; Hu, L.T.; Garcia, B.F. Academic self-efficacy and first year college student performance and adjustment. J. Educ. Psychol. 2001, 93, 55-64. [CrossRef]

26. Kahn, W.A. Psychological conditions of personal engagement and disengagement at work. Acad. Manag. J. 1990, 33, 692-724. [CrossRef]

27. Vecina, M.L.; Chacón, F.; Sueiro, M.; Barrón, A. Volunteer engagement: Does engagement predict the degree of satisfaction among new volunteers and the commitment of those who have been active longer? Appl. Psychol. 2012, 61, 130-148. [CrossRef]

28. Skaalvik, E.M.; Skaalvik, S. Teacher self-efficacy and perceived autonomy: Relations with teacher engagement, job satisfaction, and emotional exhaustion. Psychol. Rep. 2014, 114, 68-77. [CrossRef]

29. Biswas, S.; Bhatnagar, J. Mediator analysis of employee engagement: Role of perceived organizational support, P-O fit, organizational commitment and job satisfaction. Vikalpa 2013, 38, 27-40. [CrossRef]

30. Rich, B.L.; Lepine, J.A.; Crawford, E.R. Job engagement: Antecedents and effects on job performance. Acad. Manag. J. 2010, 53, 617-635. [CrossRef]

31. Karatepe, O.M. Do personal resources mediate the effect of perceived organizational support on emotional exhaustion and job outcomes? Int. J. Contemp. Hosp. Manag. 2015, 27, 4-26. [CrossRef] 
32. Aguenza, B.B.; Som, A.P.M. Motivational factors of employee retention and engagement in organizations. Int. J. Adv. Manag. Econ. 2012, 1, 88-95. [CrossRef]

33. Saks, A.M. Antecedents and consequences of employee engagement. J. Manag. Psychol. 2006, 21, 600-619. [CrossRef]

34. Wollard, K.K.; Shuck, B. Antecedents to employee engagement: A structured review of the literature. Adv. Dev. Hum. Resour. 2011, 13, 429-446. [CrossRef]

35. Singh, R.; Fouad, N.A.; Fitzpatrick, M.E.; Liu, J.P.; Cappaert, K.J.; Figuereido, C. Stemming the tide: Predicting women engineers' intentions to leave. J. Vocat. Behav. 2013, 83, 281-294. [CrossRef]

36. Schaufeli, W.B.; Taris, T.W. A Critical Review of the Job Demands-Resources Model: Implications for Improving Work and Health. In Proceedings of the Bridging Occupational, Organizational and Public Health; Springer: Dordrecht, The Netherlands, 2014; pp. 43-68.

37. Walker, C.O.; Greene, B.A.; Mansell, R.A. Identification with academics, intrinsic/extrinsic motivation, and self-efficacy as predictors of cognitive engagement. Learn. Individ. Differ. 2006, 16, 1-12. [CrossRef]

38. Connell, J.P.; Wellborn, J.G. Competence, Autonomy, and Relatedness: A Motivational Analysis of Self-system Processes; University of Rochester: Richester, NY, USA, 1990.

39. Meyer, J.P.; Gagnè, M. Employee engagement from a self-determination theory perspective. Ind. Organ. Psychol. 2008, 1, 60-62. [CrossRef]

40. Froiland, J.M.; Worrell, F.C. Intrinsic motivation, learning goals, engagement, and achievement in a diverse high school. Psychol. Sch. 2016, 53, 321-336. [CrossRef]

41. Gillet, N.; Huart, I.; Colombat, P.; Fouquereau, E. Perceived organizational support, motivation, and engagement among police officers. Prof. Psychol. Res. Pract. 2013, 44, 46-55. [CrossRef]

42. Blumenfeld, P.; Kempler, T.; Krajcik, J. Motivation and cognitive engagement in learning environments. In The Cambridge Handbook of the Learning Sciences; Sawyer, R.K., Ed.; Cambridge University Press: Cambridge, UK, 2006; pp. 475-488.

43. Dysvik, A.; Kuvaas, B. Intrinsic and extrinsic motivation as predictors of work effort: The moderating role of achievement goals. Br. J. Soc. Psychol. 2013, 52, 412-430. [CrossRef]

44. Rummel, A.; Feinberg, R. Cognitive evaluation theory: A meta-analytic review of the literature. Soc. Behav. Personal. 1988, 16, 147-164. [CrossRef]

45. Dysvik, A.; Kuvaas, B. Exploring the relative and combined influence of mastery-approach goals and work intrinsic motivation on employee turnover intention. Pers. Rev. 2010, 39, 622-638. [CrossRef]

46. Ertas, N. Turnover intentions and work motivations of millennial employees in federal service. Public Pers. Manag. 2015, 44, 401-423. [CrossRef]

47. Kuvaas, B.; Buch, R.; Weibel, A.; Dysvik, A.; Nerstad, C.G.L. Do intrinsic and extrinsic motivation relate differently to employee outcomes? J. Econ. Psychol. 2017, 61, 244-258. [CrossRef]

48. Cerasoli, C.P.; Nicklin, J.M.; Ford, M.T. Intrinsic motivation and extrinsic incentives jointly predict performance: A 40-year meta-analysis. Psychol. Bull. 2014, 140,1-29. [CrossRef] [PubMed]

49. Richer, S.F.; Blanchard, C.; Vallerand, R.J. A motivational model of work turnover. J. Appl. Soc. Psychol. 2002, 32, 2089-2113. [CrossRef]

50. Van Dijk, D.; Kluger, A.N. Task type as a moderator of positive/negative feedback effects on motivation and performance: A regulatory focus perspective. J. Organ. Behav. 2011, 32, 1084-1105. [CrossRef]

51. Anitha, J. Determinants of employee engagement and their impact on employee performance. Int. J. Product. Perform. Manag. 2014, 63, 308-323. [CrossRef]

52. Bin, A.S. The relationship between job satisfaction, job performance and employee engagement: An explorative study. Issues Bus. Manag. Econ. 2015, 4, 1-8.

53. Stajkovic, A.D.; Luthans, F. Differential effects of incentive motivators on work performance. Acad. Manag. J. 2001, 44, 580-590. [CrossRef]

54. Bandura, A. Self-efficacy: Toward a unifying theory of behavioral change. Psychol. Rev. 1977, 84, 191-215. [CrossRef]

55. Lent, R.W.; Brown, S.D.; Hackett, G. Toward a unifying social cognitive theory of career and academic interest, choice, and performance. J. Vocat. Behav. 1994, 45, 79-122. [CrossRef]

56. Schunk, D.H. Self-efficacy, motivation, and performance. J. Appl. Sport Psychol. 1995, 7, 112-137. [CrossRef]

57. Jones, G.R. Socialization tactics, self-efficacy, and newcomers' adjustments to organizations. Acad. Manag. J. 1986, 29, 262-279. [CrossRef] 
58. Guay, F.; Vallerand, R.J.; Blanchard, C. On the assessment of situational intrinsic and extrinsic motivation: The Situational Motivation Scale (SIMS). Motiv. Emot. 2000, 24, 175-213. [CrossRef]

59. Hysong, S.J.; Quiñones, M.A. The relationship between self-efficacy and performance: A meta-analysis. In Proceedings of the Twelfth Annual Conference of the Society for Industrial and Organizational Psychology, St. Louis, MO, USA, 11 April 1997.

60. Lee, C.; Bobko, P. Self-efficacy beliefs: Comparison of five measures. J. Appl. Psychol. 1994, 79, 364-369. [CrossRef]

61. Tett, R.P.; Meyer, J.P. Job satisfaction, organizational commitment, turnover intention, and turnover: Path analyses based on meta-analytic findings. Pers. Psychol. 1993, 46, 259-293. [CrossRef]

62. Konovsky, M.A.; Cropanzano, R. Perceived fairness of employee drug testing as a predictor of employee attitudes and job performance. J. Appl. Psychol. 1991, 76, 698-707. [CrossRef] [PubMed]

63. Carlson, K.D.; Wu, J. The illusion of statistical control: Control variable practice in management research. Organ. Res. Methods 2012, 15, 413-435. [CrossRef]

64. Zenger, T.R.; Lawrence, B.S. Organizational demography: The differential effects of age and tenure distributions on technical communication. Acad. Manag. J. 1989, 32, 353-376. [CrossRef]

65. Ryder, R.A. A method for estimating the potential fish production of north-temperate lakes. Trans. Am. Fish. Soc. 1965, 94, 214-218. [CrossRef]

66. Fraenkel, J.R.; Wallen, N.E. Valididity and Reliability. How to Design and Research in Education; McGraw-Hill, INC.: New York, NY, USA, 1996; Volume 3.

67. Kline, R.B. Principles and Practice of Structural Equation Modeling, 2nd ed.; Guilford Press: New York, NY, USA, 2005; p. xviii, 366.

68. Hair, J.F. Multivariate Data Analysis; Pearson Education India: London, UK, 2006.

69. Aiken, L.S.; West, S.G.; Reno, R.R. Multiple Regression: Testing and Interpreting Interactions; Sage Publications: Newbury Park, CA, USA, 1991.

70. Zhang, X.; Bartol, K.M. Linking empowering leadership and employee creativity: The influence of psychological empowerment, intrinsic motivation, and creative process engagement. Acad. Manag. J. 2010, 53, 107-128. [CrossRef]

71. Pierce, W.D.; Cameron, J.; Banko, K.M.; So, S. Positive effects of rewards and performance standards on intrinsic motivation. Psychol. Rec. 2003, 53, 561-578. [CrossRef]

72. ten Brummelhuis, L.L.; ter Hoeven, C.L.; Bakker, A.B.; Peper, B. Breaking through the loss cycle of burnout: The role of motivation. J. Occup. Organ. Psychol. 2011, 84, 268-287. [CrossRef]

73. Deci, E.L.; Nezlek, J.; Sheinman, L. Characteristics of the rewarder and intrinsic motivation of the rewardee. J. Personal. Soc. Psychol. 1981, 40,1-10.

74. Deci, E.L. Effects of externally mediated rewards on intrinsic motivation. J. Personal. Soc. Psychol. 1971, 18, 105-115. [CrossRef]

75. Ilgen, D.; Davis, C. Bearing bad news: Reactions to negative performance feedback. Appl. Psychol. 2000, 49, 550-565. [CrossRef]

76. Hufton, N.R.; Elliott, J.G.; Illushin, L. Educational motivation and engagement: Qualitative accounts from three countries. Br. Educ. Res. J. 2002, 28, 265-289. [CrossRef]

77. Martin, A.J. Examining a multidimensional model of student motivation and engagement using a construct validation approach. Br. J. Educ. Psychol. 2007, 77, 413-440. [CrossRef]

78. Skinner, B.F. Contingencies of Reinforcement: A Theoretical Analysis; B. F. Skinner Foundation: Cambridge, MA, USA, 2014.

79. Badami, R.; VaezMousavi, M.; Wulf, G.; Namazizadeh, M. Feedback after good versus poor trials affects intrinsic motivation. Res. Q. Exerc. Sport 2011, 82, 360-364. [CrossRef]

(C) 2020 by the authors. Licensee MDPI, Basel, Switzerland. This article is an open access article distributed under the terms and conditions of the Creative Commons Attribution (CC BY) license (http://creativecommons.org/licenses/by/4.0/). 